\title{
Extended Reality (XR) and Cloud-Based BIM Platform Development
}

\author{
Fabrizio Banfi
}

\section{Abstract}

Extended reality (XR), Artificial Intelligence (Al) and Building Information Modeling (BIM) for the digitization of cultural heritage are proving remarkably successful in different fields of application. The convergence of innovative methods, latest-generation technologies, and software applications for the representation, storage, transmission of tangible and intangible values of architecture, turn out to be increasingly decisive both in supporting the project's needs of the professionals involved in the valorisation and management of the built cultural heritage and in enhancing the transmission of computer-generated perceptual information for all types of users (expert and non-expert). For those reasons, this article presents research focused on the development of an open-source cloudbased BIM platform and XR projects capable of sharing a knowledge process based on new levels of interactivity and digital creativity.

Keywords

extended reality $(X R)$, artificial intelligence $(\mathrm{Al})$, cloud-based BIM platform, interactivity.

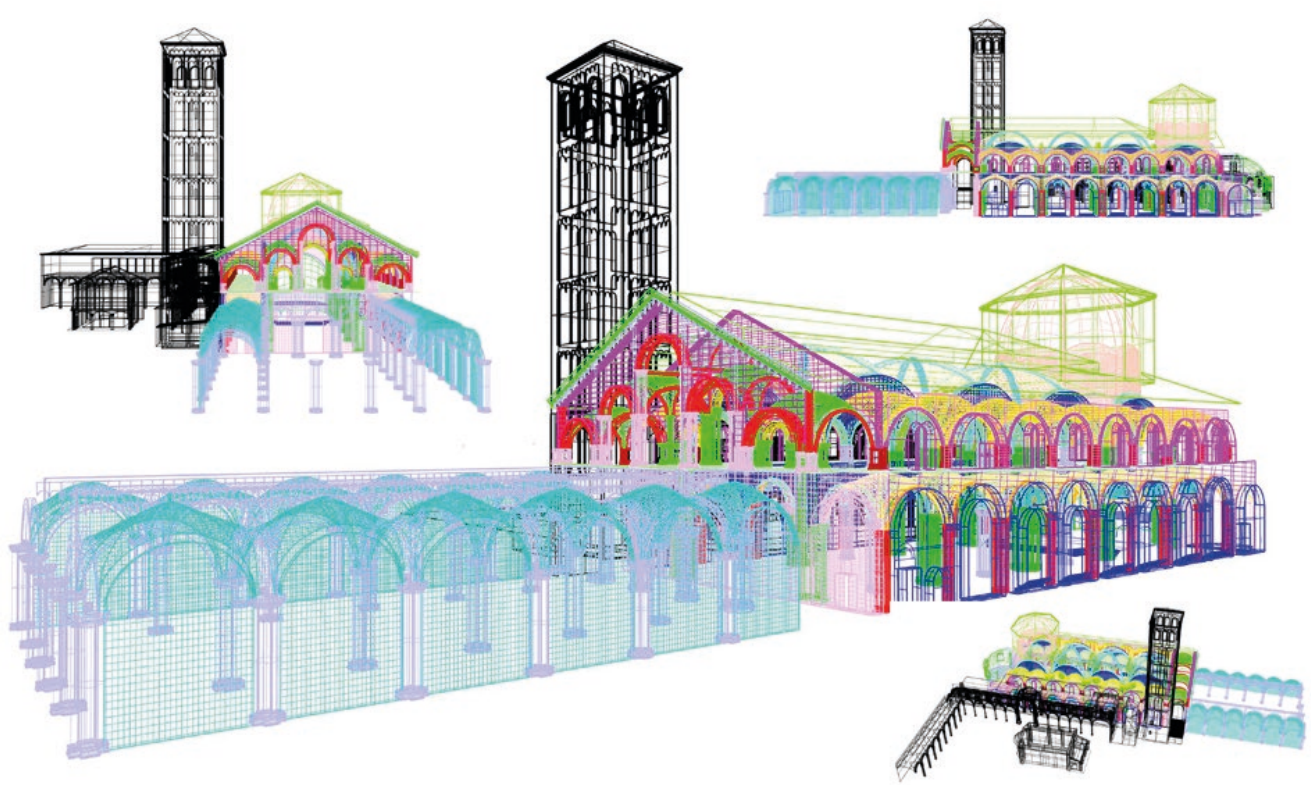




\section{Scan-to-BIM Process Meets Computer Science Development and APIs}

Emerging technologies such as eXtended reality (XR), artificial intelligence (Al) and building information modeling (BIM) provide innovative opportunities to increase the transmission of tangible and intangible values of heritage buildings during the building life cycle and integrated design process [Alizadehsalehi 2020]. In the digital cultural heritage (DCH) domain, the transmissibility of those values is crucial during the processes aimed at the preservation and restoration of buildings. The interdisciplinary nature of these processes requires interactive environments capable of sharing a large amount of data in real-time among all the professionals involved in the process [Banfi 2020, pp. 16-33].

In recent years, innovative results have been found in various fields of application such as entertainment, gaming, healthcare, marketing and consumers, retail and education. At the same time, sectors such as architecture, engineering and construction (AEC) industry, arts and design, real estate, tourism, and automotive industry, have benefited from new state-of-the-art tools (software and hardware) capable of increasing the levels of interactivity, immersion and knowledge of digital models [Banfi, Oreni 2020, pp. I I - | 36; Brumana et al. 2020, pp. 39 I -400]. Accordingly, the challenge to create new and increasingly innovative solutions able to support experts in DCH domain has been taken up by various institutions, research centres and European projects [Alizadehsalehi 2020]. For all those reasons, the aim of this research was to create a digital repository capable of enhancing the use of informative models deriving from a scan-to-BIM process capable of effectively representing the reality detected through which is possible to share a huge amount of building information (fig. I).

Scan-to-BIM process, Al and cloud system have been extensively investigated in various forms, methods and projects in the last decade [Giordano et al. 20 I8, pp. 50-73; Graham,

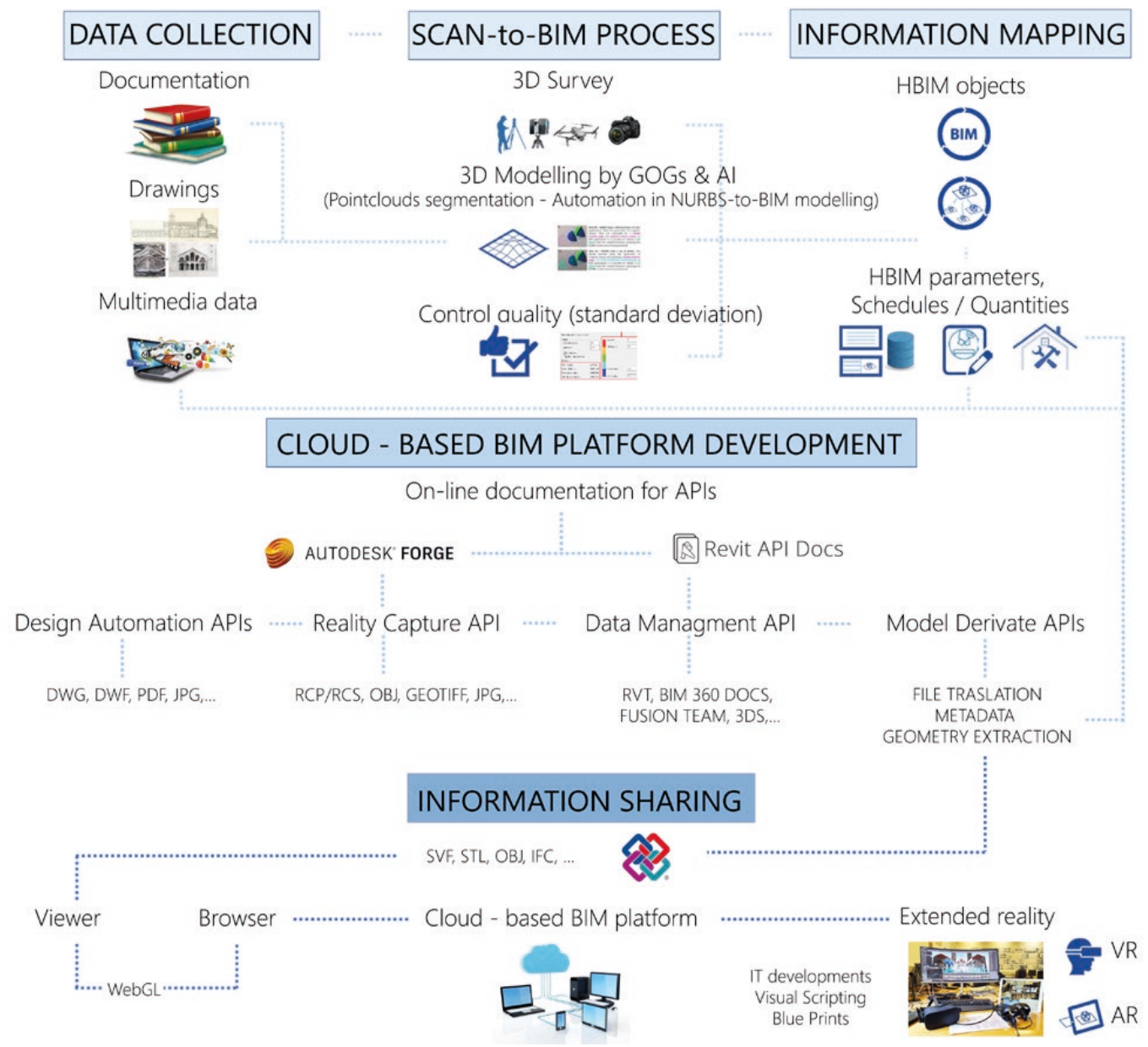


Chow, Fai 2019, pp. 553-568; loannides, Magnenat-Thalmann, Papagiannakis 20 I7]. Several types of research have shown how the integration of those disciplines allows professionals to lay the best possible bases for all those types of BIM - based analysis that require high levels of detail (LOD) and information (LOI) such as structural analysis, building monitoring, infrastructures (InfraBIM), energy analysis, advanced prototyping, plant engineering, scheduled maintenance, construction site and restoration [Luigini et al. 2018, pp. 288-302; Oreni et al. 2017, pp. 153-I58; Porro, Cocchiarella 2019, pp. 40-56]. Furthermore, several cloud solutions have been proposed by the main software developers such as Autodesk, Graphisoft and Bentley to host a large quantity of data (models and information) in a shared form. Besides, online applications such as Autodesk A360, BimX have demonstrated how through new exchange formats (proprietary and open-source) it is possible to share the wealth included in digital models via a web interface within everyone's reach. The next challenge, therefore, was to share geometry and the contents in a single solution and through different types of devices (PC, mobile phone, tablet and VR headset) e 3D exchange formats (proprietary and open-source), supporting different types of users in their own daily practices and operations in real-time (fig. 2).

The research and development activity conducted in the last two years by the author focused on reaching new forms of interaction, immersion and sharing through the creation of an opensource cloud BIM-based platform capable of sharing different types of data such as materials, building techniques, monitoring data, schedules/quantities and digital drawings. Thanks to definition of novel Grades of Generation (GOG) based on Al,pointcloud segmentation and automation in NURBS-to-BIM modelling has been possible to digitalized the reality with high LODs and accuracy [Banfi 2020, pp. 16-33]. The next paragraph describes the research-development process that led to the creation of this platform, focusing on the development and sharing of the main $\mathrm{XR}$ and HBIM projects developed in recent years. In particular, the Basilica of Collemaggio in L' Aquila, the Basilica of Sant'Ambrogio and the Azzone Visconti bridge in Lecco, represent the main case studies developed and included in this digital library, but at the same time, they represent a starting point for an open development logic and new levels of interoperability and sharing ready to welcome other experiences and architectural artifacts of high historical and cultural value.

\section{Model Interoperability: Cloud-Based BIM Platform and Extended Reality (XR) Projects}

Tests and analyzes conducted on the new paradigm of interaction between the real and virtual world and thanks to the implementation of new scan-to-BIM requirements (GOGs based on Al, pointcloud segmentation and automation in NURBS-to-BIM modelling), computer languages and application programming interfaces (APIs), it was possible to create an interactive data

Upload IFC in the Cloud

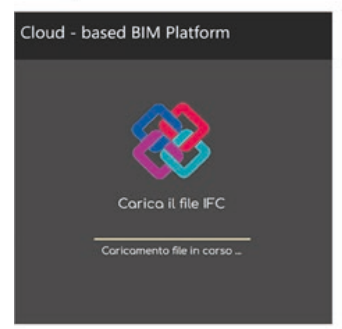

Basilica of Collemaggio
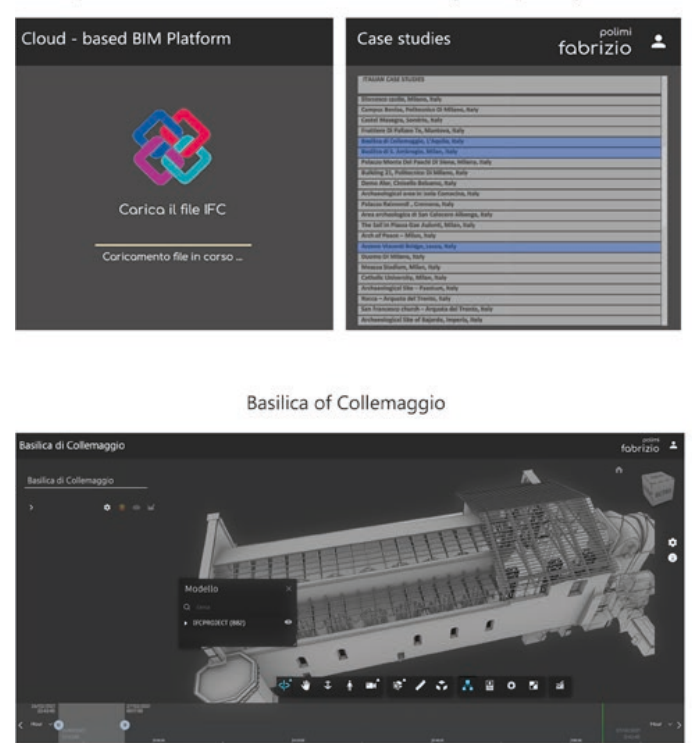

Azzone Visconti bridge

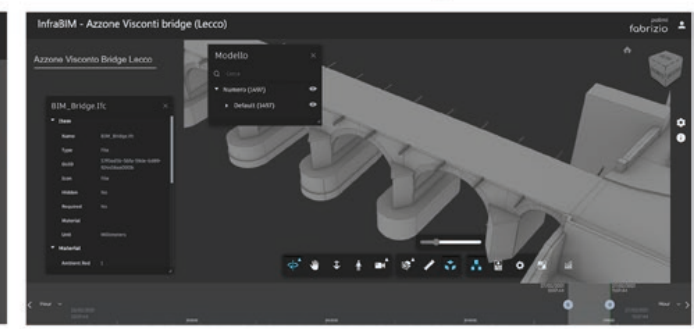

Basilica of Sant'Ambrogio

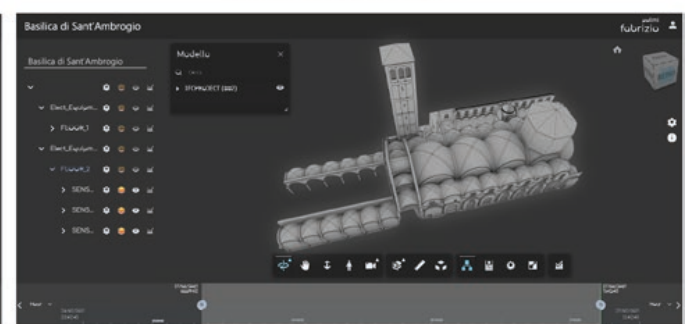

Fig. 2. The developed platform and the display platform and the disp
of different type of projects. 
repository composed of case studies of national and international interest, integrating various ways of real-time visualization of digital models. In particular, thanks to the Forge Platform and Revit APIs doc which offerWeb-based, searchable, and extensible API documentation, it is possible to undertake IT development process oriented to the creation of custom digital hub for different research case studies. Design and building a viewer that converts and displays models on a browser favoured high level of information sharing, moving from professional and proprietary platforms/formats to an open-source logig. As shown in figure 2, BIM modeles (as-found, as-designed and as-built projects), once uploaded to cloud using the IFC (Industry Foundation Classes) format, can be explored, modified, commented and analysed. Furthermore the developed platform allow the upload and download of a many varieties of data type such as Viewable 2D and 3D design file formats (3DM, 3DS, ASM, CAM360, CATPART, CATPRODUCT, CGR, DAE, DLV3, DWF, DWFX, DWG, DWT, EXP, F3D, FBX, GBXML, IAM, IDW, IFC, IGE, IGES, IGS, IPT, JT, MODEL, NEU, NWC, NWD, OBJ, PRT, RVT, SAB, SAT, SESSION, SKP, SLDASM, SLDPRT, SMB, SMT, STE, STEP, STL, STLA, STLB, STP,WIRE, X_B, X_T, XAS, XPR), media and office file formats (AVI, GIF, JPG, PNG,TIFF, DOC, PDF, PPT,TXT, XLS,...). It should be emphasized that the export of the BIM project in the open IFC format and the subsequent upload of the file to cloud platform has avoided the loss of the information previously included in the BIM model, favouring a easily 3D / 2D read by expert and non-expert users. Thanks to a simplified interface, user can select each BIM objects and read all the parameters and information previously inserted and connected to the BIM project. This last phase has allowed one to move from a digital logic based on proprietary files to an open common data environment (CDE) and real-time sharing. Finally, thanks to the level of interoperability achieved the final development step was to include the ability to share VR and AR projects (developed using Unreal Engine ad its visual scripting Blue Prints) via multiple devices and HBIM models at the same time. Figure 3 shows the multiple configuration and devices which could be used for dynamic access to data and digital models enabling them to immersive projects that expand our real-world and combine it with virtual elements and contents.

\section{Research Results and Future Prospectives}

The cloud BIM-based platform developed allows the sharing of BIM projects, the remote immersion in eXtended reality $(X R)$ projects and the implementation of an augmented reality (AR) library of architectural, artistic, historical elements cultural and unique of their kind. The main results of this research development process are:
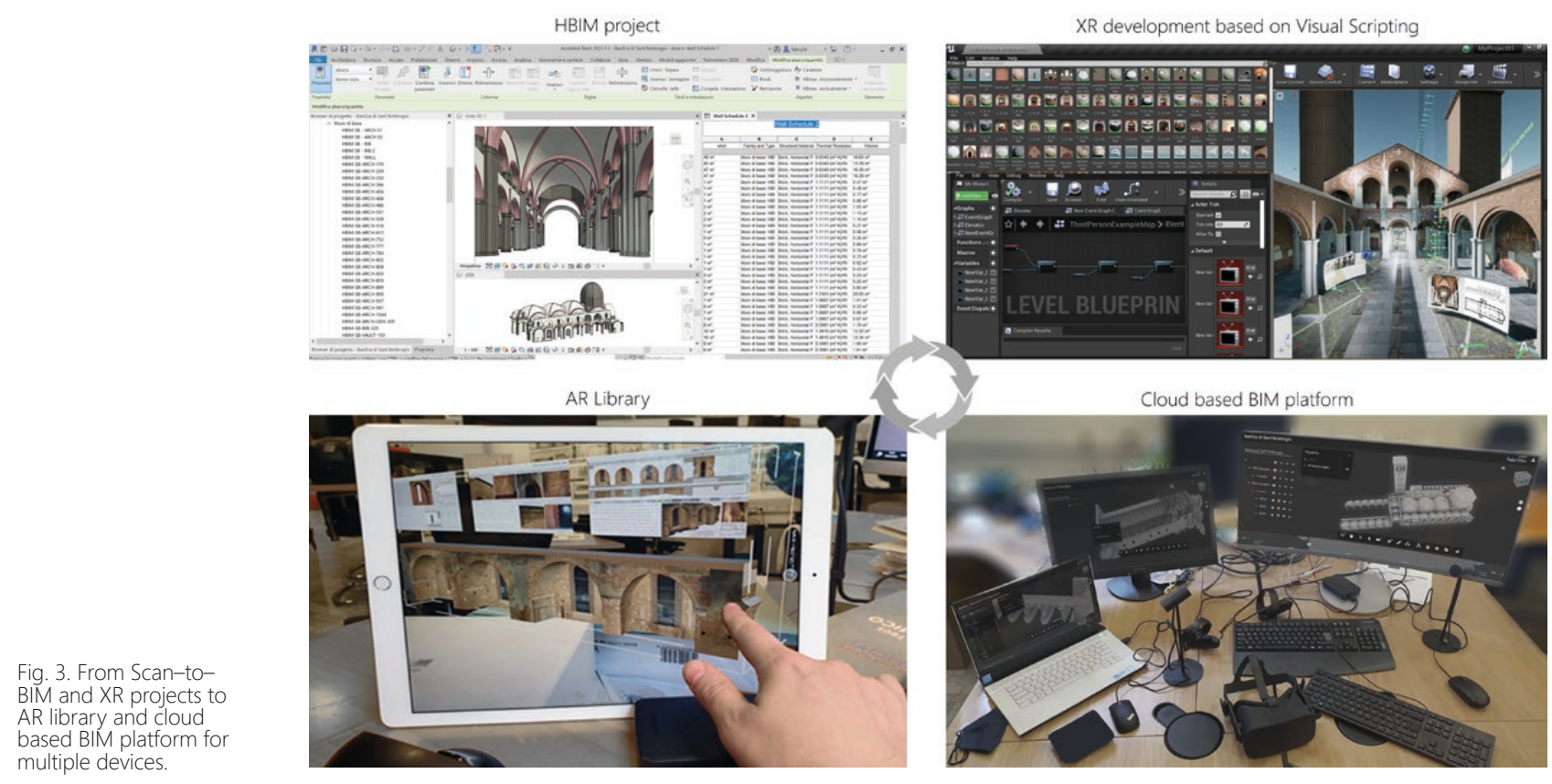

Cloud based BIM platform

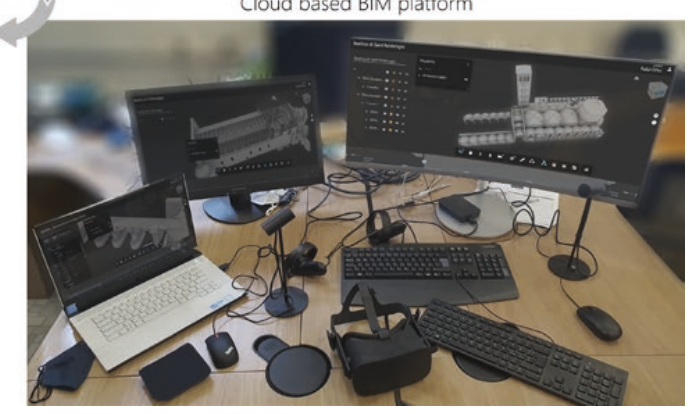


- creation of a cloud platform capable of hosting and sharing scan-to-BIM projects characterized by the use of a large quantity of data such as point clouds coming from laser scanning and digital photogrammetry (primary data sources) and historical reports, digital drawings, multimedia files (secondary data sources);

- greater coordination and collaboration, efficient workflows, user friendly 3D visualizations and better project results

- making VR projects more accessible by sharing executable files for the installation of dedicated apps for each project developed;

- implementation and sharing of AR objects,

- improvement of the levels of interoperability of digital models through the use of exchange formats (proprietary and open-source).

- diversified modes of use through smart glasses,VR headsets, PCs, mobile phones and tablets. Future developments are oriented to increase the level of interactivity of the cloud platform thanks to the connection of data coming from monitoring. The final goal will be to integrate digital models and real-time data into one digital solution, helping to increase the awareness and intangible values of our built heritage.

\section{Acknoldgements}

Research leading to this results is partially funded by Regione Lombardia- Bando "Smart Living: integrazione fra produzione servizi e tecnologia nella filiera costruzionilegno-arredo-casa" approvato con d.d.u.o. n. I I 672 dell' I 5 novembre 2016 nell'ambito del progetto "HOMeBIM liveAPP: Sviluppo di una Live APP multi-utente della realtà virtuale abitativa 4D per il miglioramento di comfort-efficienza-costi, da una piattaforma cloud che controlla nel tempo il flusso BIM-sensori - ID 379270".

\section{References}

A.A.V.V. (2017). In loannides Marinos, Magnenat-Thalmann Nadia, Papagiannakis George (eds.). Mixed Reality and Gamification for Cultural Heritage. Cham: Springer.

Alizadehsalehi Sepehr, Hadavi Ahmad, Huang Joseph Chuenhuei (2020). From BIM to extended reality in AEC industry. In Automation in Construction, I 16, 103254.

Banfi Fabrizio (2020). HBIM, 3D drawing and virtual reality for archaeological sites and ancient ruins. In Virtual Archaeology Review, I I (23), pp. I6-33.

Banfi Fabrizio, Oreni Daniela (2020). Virtual Reality (VR), Augmented Reality (AR), and Historic Building Information Modeling (HBIM) for Built Heritage Enhancement: From Geometric Primitives to the Storytelling of a Complex Building. In Impact of Industry 4.0 on Architecture and Cultural Heritage. Hershey: IGI Global, pp. I I I I 36.

Brumana Raffaella, Oreni Daniela, Barazzetti Luigi, Cuca Branka, Previtali Mattia, Banfi Fabrizio (2020). Survey and Scan to BIM Model for the Knowledge of Built Heritage and the Management of Conservation Activities. In Digital Transformation of the Design, Construction and Management Processes of the Built Environment. Cham: Springer, pp. 391-400.

Giordano Andrea, Bernardello Rachele, Borin Paolo, Friso Isabella, Monteleone Cosimo, Panarotto (20 I8). Rappresentazione/ Representation - Le opportunità fornite dai nuovi strumenti digitali - The opportunities of the new digital tools. In Paesaggio Urbano, 4, pp. 50-73.

Graham Katie, Chow Lara, Fai Stephen (2019). From BIM to VR: defining a level of detail to guide virtual reality narratives. In Journal of Information Technology in Construction, 24, pp. 553-568.

Luigini Alessandro, Massari Giovanna A., Vattano Starlight, Pellegatta Cristina, Luce Fabio (20I8). Visual Culture and Cultural Heritage: $\mathrm{ViC}-\mathrm{CH}$ a Synthesis Between Digital Representation and Heritage Experience. In International and Interdisciplinary Conference on Digital Environments for Education, Arts and Heritage. Cham: Springer, pp. 288-302.

Oreni Daniela, Brumana Raffaella, Della Torre Stefano, Banfi Fabrizio (2017). Disegno e modellazione parametrica per la conservazione di un edificio monumentale danneggiato da un evento sismico. Dal rilievo al cantiere. In ANANKE Speciale Geores, pp. 153-158.

Porro Simone, Cocchiarella Luigi (2019). Use of a Game Engine Artificial Intelligence to Represent People Flows in Architectural Spaces via Geometry and Graphics. In KoG, 23 (23), pp. 40-56.

Wong Johnny, Wang Xiangyu, Li Heng, Chan Greg, Li Haijiang (20I4). A review of cloud-based BIM technology in the construction sector. In Journal of information technology in construction, 19, pp. 281-291.

Author

Fabrizio Banfi, Dept. of Architecture, Built Environment and Construction Engineering, Politecnico di Milano, fabrizio.banfi@polimi.it 
